\title{
SIZE-BASED RESPONSES OF PREY TO PISCIVORE EXCLUSION IN A SPECIES-RICH NEOTROPICAL RIVER
}

\author{
Craig A. Layman ${ }^{1}$ and Kirk O. Winemiller \\ Section of Ecology and Evolutionary Biology, Department of Wildlife and Fisheries Sciences, 210 Nagle Hall, \\ Texas A\&M University, College Station, Texas 77843-2258 USA
}

\begin{abstract}
Characteristics used to group species, and thus generalize ecological interactions, can aid in constructing predictive models in species-rich food webs. We tested whether size could be used to predict a behavioral response of multiple prey species $(n>$ 50) to exclusion of large-bodied fishes, including seven abundant piscivore species, in a lowland Neotropical river. A randomized block design $(n=6)$ included three experimental treatments constructed on sandbank habitats: large fish exclusion, cage control (barrier with gaps), and natural reference plot (no barrier). Exclosures prevented passage of all largebodied fishes, but the mesh size allowed passage of prey fishes. After two weeks, experimental areas were sampled once during the day and once at night. Total abundance of prey fishes was not significantly different among treatments, and effects on species density were variable. Analyses based on fish size class, however, demonstrated significant sizebased effects of large-fish exclusion. Abundance of medium fishes $(40-110 \mathrm{~mm})$ in exclusion treatments increased significantly relative to controls in day (248\%) and night $(91 \%)$ samples, and this trend was apparent for many species $(n>13)$. Species density of medium fishes increased significantly in exclusion treatments. There was evidence of an intraspecific, size-dependent response for the three most common species. Ninety percent of prey in stomach contents of seven common large-bodied piscivores (collected from river sandbanks) were $40-110 \mathrm{~mm}$, corresponding to size of fishes that responded to large-fish exclusion. Behavioral responses of medium prey likely resulted from exclusion of these large-bodied piscivores. These results extend size-based predator avoidance behavior demonstrated in temperate systems to a highly connected tropical river food web. In this species-rich web, size is a strong predictor of behavioral responses of multiple prey species to large piscivores, and it can be used to generalize outcomes of multiple species interacting simultaneously.
\end{abstract}

Key words: complexity; diversity; fish; food webs; indirect effects; predator-prey interactions; river; size structure; tropics; Venezuela.

\section{INTRODUCTION}

Developing predictive models of species interactions is challenging, especially in diverse communities. Much of the world's species diversity is located in tropical ecosystems, and a better understanding of species interactions is necessary to help stem biodiversity loss and assess community-level responses to human-induced habitat change. In species-rich food webs, extending the logic of pair-wise predator-prey interactions often will not predict outcomes of multiple species interactions (Wilbur and Fauth 1990, Polis and Strong 1996, Schmitz 1998). For example, effects of multiple predators on prey populations might not be additive (Wootton 1994, Sih et al. 1998, Eklöv and VanKooten 2001). Indirect effects become increasingly complex in speciose food webs (Fox and Olsen 2000), rendering it difficult to make predictions when many species interact simultaneously (Abrams 1992, Kle-

Manuscript received 9 December 2002; revised 11 September 2003; accepted 22 September 2003. Corresponding Editor: A. S. Flecker.

${ }^{1}$ E-mail: cal1634@yahoo.com banoff and Hastings 1994, Yodzis 2000, Wootton 2001, Relyea and Yurewicz 2002).

Body size is an important determinant of predatorprey interactions and is used to predict behavioral responses to predation threat in aquatic systems. Body size predicted avoidance behavior by bluegill, Lepomis macrochirus, in response to presence of predatory largemouth bass, Micropterus salmoides (Werner et al. 1983, Werner and Hall 1988, Turner and Mittelbach 1990). In streams, small prey fishes move into shallow water in the presence of largemouth bass, but larger fishes do not alter their distribution patterns (Harvey 1991). In Trinidad, body size of the killifish Rivulus hartii is a determinant of movements within a river and among tributaries in the presence of the piscivore $\mathrm{Ho}$ plias malabaricus (Gilliam and Fraser 2001). Steinmetz et al. (2003) demonstrated in two temperate streams that fish response to bird predation is size dependent. The importance of such induced behavioral responses at both community and ecosystem levels is becoming increasingly clear (Luttbeg and. Schmitz 2000, Lima 2002).

Few studies have manipulated multiple predators and evaluated behavioral responses of multiple prey (Woot- 


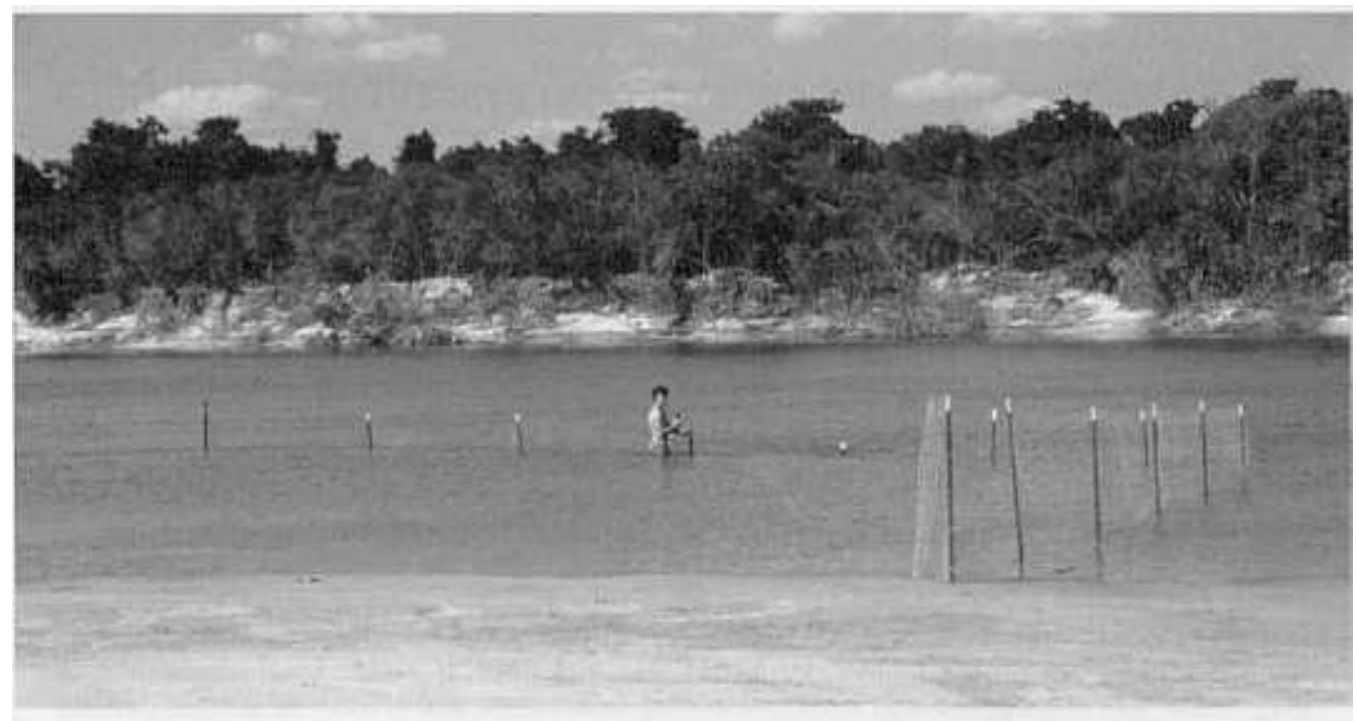

Fin. 1. Exnerimental exclosure on a Rín Cinaruen kandhank:

ton 1993, Marquis and Whelan 1994, Dial and Roughgarden 1995, Greenberg et al. 2000, Nyström et al. 2001, Relyea and Yurewicz 2002), and none of this work has been conducted in tropical aquatic systems. Here, we tested for a behavioral response of multiple prey species $(n>50)$ to multiple piscivore species ( $n$ $>7$ ) using large experimental exclosures $\left(\sim 500 \mathrm{~m}^{2}\right)$. We examined if prey alter their spatial distribution in the absence of piscivores (e.g., peacock cichlids Cichla spp.) in a species-rich tropical river with a highly connected food web. All large-bodied fishes were excluded, but prey were able to pass in and out of experimental areas. To test if size is a useful predictive variable of piscivore effects on prey fish assemblages, we a priori divided potential prey fish into size categories and evaluated results based on these groupings. We tested the null hypothesis that there would be no difference in fish abundance or species density among experimental treatments, regardless of fish size.

\section{Study Site}

The study was conducted in the Río Cinaruco, a blackwater, floodplain river in southwestern Venezuela $\left(6^{\circ} 32^{\prime} \mathrm{N}, 67^{\circ} 24^{\prime} \mathrm{W}\right)$. The river is strongly seasonal with water levels fluctuating $>5 \mathrm{~m}$ in an annual hydroperiod. During the dry season (January-April), the main river channel contains long ( $\leq 2 \mathrm{~km}$ ), broad sandbanks that constitute a large proportion of river shoreline. River width in the dry season is $40-200 \mathrm{~m}$, water temperatures typically range from $28^{\circ}$ to $36^{\circ} \mathrm{C}$, Secchi depths are $\sim 1 \mathrm{~m}$ in the main river channel adjacent to beaches, and dissolved oxygen is always near saturation in the main channel.

The river supports $\geq 260$ fish species that span an extremely wide range of ecological attributes and life history strategies. In previous (Jepsen et al. 1997, Winemiller and Jepsen 1998) and ongoing research, seven species have been identified as the most common largebodied (total length $>350 \mathrm{~mm}$ ) piscivores of sandbank habitats where experiments were conducted: peacock cichlids (Cichla intermedia, $C$. orinocensis, and $C$. temensis), characiforms (Boulengerella cuvieri, B. lucius, and Hydrolycus armatus), and a pimelodid catfish (Pseudoplatystoma fasciatum). These species are relatively mobile predators that often forage on river sandbanks. Based on three years of sampling with a variety of techniques (e.g., gill netting, hook-and-line fishing), we estimate occurrence of these large piscivores typically ranges from 5 to 40 individuals per $75-\mathrm{m}$ stretch of sandbank over a 24-h period (C. A. Layman, unpublished manuscript).

Four piranha species (Serralsalmus spp., Pristobrycon spp.) are abundant in the river, but are not considered here because they primarily inhabit deeper areas of the main river channel and floodplain lagoons. River dolphin, Inia geoffrensis, also feed in deeper areas, not on sandbanks, and are far less dense than piscivorous fishes (McGuire and Winemiller 1998). Spectacled caiman, Caiman crocodilus, and birds (e.g., Osprey, Pandion haliaetus; Cocoi Heron, Ardea cocoi) could feed in all experimental areas equally, but were never observed feeding in any treatment.

\section{METHODS}

We employed a randomized block design, with each block $(n=6)$ placed in a different location and different time during January-March 2001. Each block consisted of three treatments arranged in random order in the littoral region of a sandbank. Exclosure treatments were constructed with $60 \mathrm{~m}$ of poultry wire (mesh $2.5 \mathrm{~cm}$ ) attached with plastic ties to $1.8-\mathrm{m}$ metal posts spaced at 5-m intervals. The wire barrier was arranged in an elongated semicircle shape along $\sim 35$ $\mathrm{m}$ of sandbank to enclose an area of $\sim 500 \mathrm{~m}^{2}$ (Fig. 1). 
The wire mesh was pushed $\geq 5 \mathrm{~cm}$ into the substrate along the entire enclosure length. This design excluded all large-bodied fishes from passing into exclosures, while allowing full movement of most prey of excluded large-bodied piscivores. Control treatments included $60 \mathrm{~m}$ of wire, but with two 5-m gaps (in deeper water at the exclosure back) that allowed fishes of all sizes to move in and out freely. We observed Cichla spp. and Boulengerella spp. feeding inside control treatments and just outside exclosures, suggesting presence of the wire did not substantially affect natural feeding behavior. Natural reference plots were comparable sandbank areas without wire or posts. The three experimental areas within a block were separated by 50 $m$ of unmanipulated beach.

After approximately two weeks, experimental areas were sampled during the day and night using a seine $(6.4 \times 1.8 \mathrm{~m}, 4-\mathrm{mm}$ mesh). During the day, one sample consisted of three hauls made parallel to the beach with one end of the seine pulled along the shoreline. Each seine haul was conducted along a different $10-\mathrm{m}$ stretch of beach within the experimental area. Deepwater seine hauls ( $n=3$ in each experimental area) were initiated at the back of the enclosure, and the seine was hauled directly toward shore. Nighttime seine hauls were conducted only along the shoreline $(n=3$ in each experimental area) due to safety concerns of sampling deeper water at night. Day and night samples were not pooled due to differences in sampling methodology (i.e., no deepwater seine hauls at night) and due to differences in assemblage composition between day and night samples (Arrington and Winemiller 2003). Specimens were preserved and transported to the Universidad de Los Llanos Occidentales (UNELLEZ) in Guanare, Venezuela. Individuals were identified to species and enumerated. Voucher specimens were archived in the $\mathrm{Mu}-$ seo de Ciencias Naturales at UNELLEZ and the Texas Cooperative Wildlife Collection, College Station, Texas, USA.

Due to logistical constraints of measuring every individual fish $(n>14000)$, analyses were based on two size classes established a priori (small, $<40 \mathrm{~mm}$; medium, $>40 \mathrm{~mm}$ ), and not exact lengths of individuals. Size categories commonly are used to establish feeding relationships and examine outcomes of ecologìcal interactions (Peterson and Andre 1980, Dial and Roughgarden 1995, Schoener and Spiller 1999, Greenberg et al. 2000, Spiller and Schoener 2001, Schoener et al. 2002). For example, Schoener et al. (2002) used size categories of arthropods ( $>4 \mathrm{~mm}$ and $<4 \mathrm{~mm}$ ) to describe food web differences on islands with and without the lizard predator Leiocephalus carinatus. Use of size categories reduces power to detect subtle size-based differences, but facilitates analysis of large samples.

A substantial proportion of species in the river mature at sizes $<40 \mathrm{~mm}$, including dozens of small characid species that are extremely common on sandy beach habitats (Arrington and Winemiller 2003). In the pres- ent study, "small" fishes refer to all fishes $<40 \mathrm{~mm}$, irrespective of maturation status. Depending on methodology (e.g., net dimensions, mesh size) and site, 79$100 \%$ of fishes on sandbanks have been estimated to be $<40 \mathrm{~mm}$ in length (C. A. Layman and K. O. Winemiller, unpublished manuscript). The largest fish collected in experimental areas was $110 \mathrm{~mm}$, so all fishes within 40 to $110 \mathrm{~mm}$ were categorized as "medium." Potential prey fishes on sandbanks are highly diverse, both taxonomically ( 81 genera, 24 families) and functionally (i.e., in terms of feeding strategy, habitat utilization).

We also analyzed stomach contents of the seven most common piscivore species. From January to April during both 2001 and 2002, piscivores were collected on sandbank habitats where the experiments were conducted and on other nearby sandbanks. Fishes were collected with gill nets, and by hook and line using artificial lures. Fishes were measured (standard length [SL], $\pm 1.0 \mathrm{~mm}$ ) and stomachs were analyzed using one of two methods. Cichla temensis, $C$. orinocensis, $C$. intermedia, and Pseudoplatystoma fasciatum stomachs were examined by pressing down the posterior region of the tongue and pushing gently on the fish's stomach while holding the fish in a head-down position. Subsequent dissection of a subset of individuals $(n=71)$ confirmed this method is $100 \%$ effective in recovering stomach contents, regardless of prey size. Boulengerella cuvieri, B. lucius, and Hydrolycus armatus were euthanized, and stomachs removed for examination. Data were pooled for the seven species to provide a composite view of size of prey consumed by large piscivores on sandbanks.

\section{Statistical ANalysis}

The two aggregate response variables analyzed were fish abundance and species density. Abundance was total number of individuals collected by standardized seining of a fixed area within each treatment; species density (following Gotelli and Colwell [2001]) was expressed as number of species collected in the standardized seining area. Analyses were conducted (separately for day and night) using a randomized-block ANOVA on overall fish abundance and species density, as well as on medium and small size classes independently. Medium fish, but not small individuals, responded to piscivore exclusion (see Results), so additional analyses were conducted on the medium size class.

Specifically, we wanted to know if overall response of medium fishes (Fig. 2) was attributable to similar patterns of response by multiple taxa. To control for the effect of between-species differences in total abundance, we converted raw species abundance values to $Z$ scores within each block of the experiment. The $Z$ scores were calculated as follows:

$$
Z=\left(X_{i}-\mu\right) / \sigma
$$




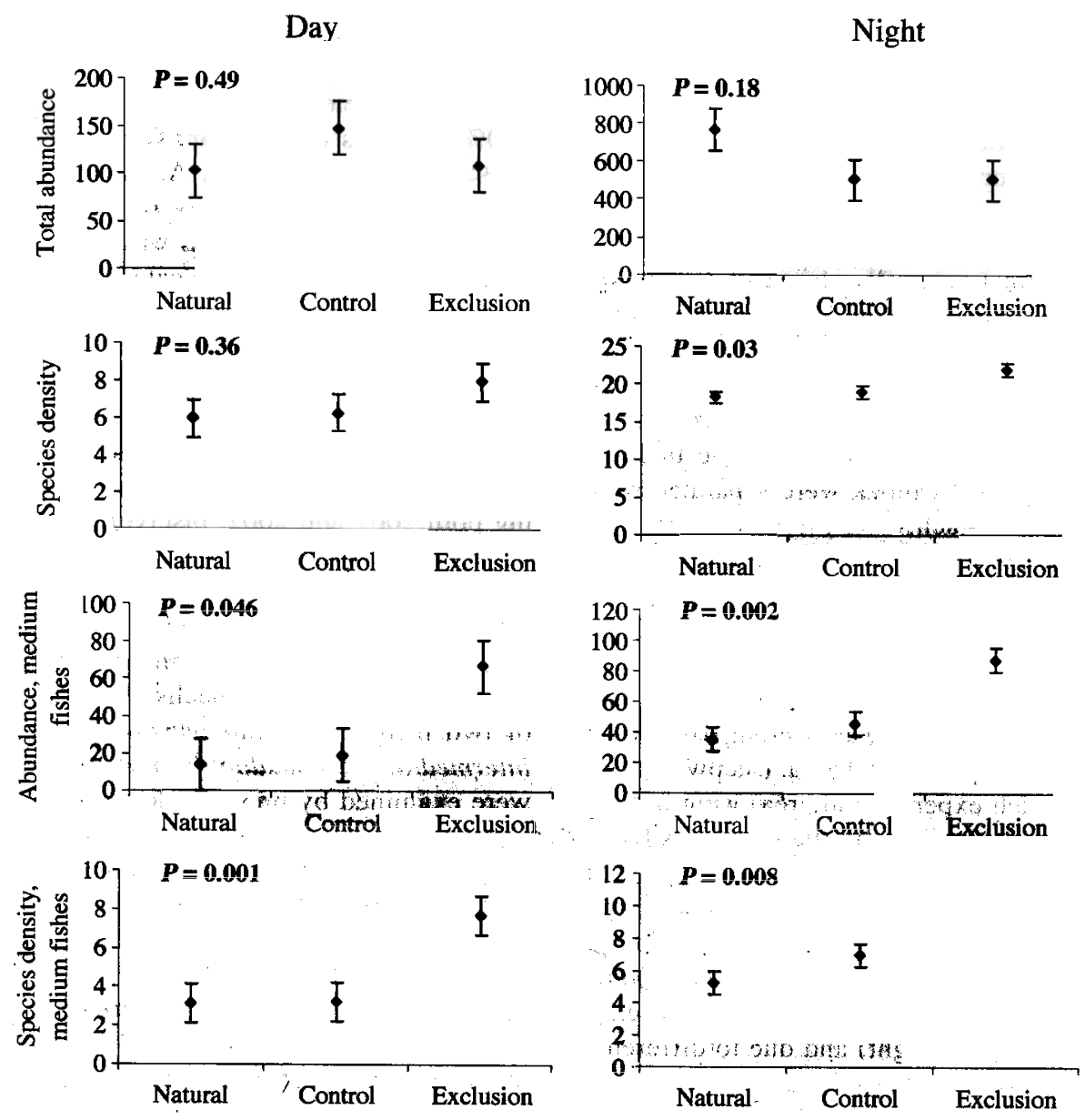

FIG. 2. Least-squares means of total abundance and species density of all fishes (top two rows) and medium fishes (40$110 \mathrm{~mm}$; bottom two rows) within experimental areas. Total abundance is the number of individuals collected by standardized seine sampling; species density is the number of species collected in this same area. The left column reports day sampling; the right column reports night sampling. $P$ values are from ANOVA on response variables with significant values in boldface. Error bars represent \pm 1 SE.

where $X_{i}$ is the abundance of the $i$ th species in one treatment of an experimental block and $\mu$ and $\sigma$ are the mean and standard deviation, respectively, of the three abundance values for the $i$ th species in that block (Fig. 3; Zar 1996). A multivariate analysis of variance (MANOVA) was conducted separately for day and night samples, with experimental treatment as the independent variable and species standardized abundance (i.e., $\boldsymbol{Z}$ score) as the dependent variable. Rare species were excluded from the analysis (species with $<10$ individuals collected), because there were not enough degrees of freedom to conduct MANOVA with all species included. Significant MANOVA results are followed by univariate tests (i.e., one-way ANOVA) for each species examining abundance differences among treatments (Scheiner and Gurevitch 2001).

For those species in which individuals $<40 \mathrm{~mm}$ and $>40 \mathrm{~mm}$ were colleeted in more than half of the blocks, we also tested for a size-based intraspecific response. Contingency tables were inappropriate for these anal- yses, as expected cell values were low due to high variability in presence of individuals among blocks. Abundance of individuals $<40 \mathrm{~mm}$ and $>40 \mathrm{~mm}$ were standardized to $Z$ scores within each block as described. Standardized abundance ( $Z$ score) then was analyzed using ANOVA and Tukey's post hoc test. Analyses were conducted using JMP software (Version 4.04, SAS Institute, Inc, Cary, North Carolina, USA).

To best assess assemblage structure and dynamics, both aggregate (e.g., abundance and species density) and composition measures should be used in analyses (Micheli et al. 1999). Correspondence analysis (CA), a composition-based technique, was used to determine if particular assemblages of fish were representative of given treatments. Correspondence analysis is an indirect technique used to detect gradients in species composition from observed species abundance (Hill and Gauch 1980, Peet et al. 1988). Here, CA was conducted using CANOCO 4 (ter Braak and Šmilauer 1998). Canonical ordination scores were analyzed to assess 


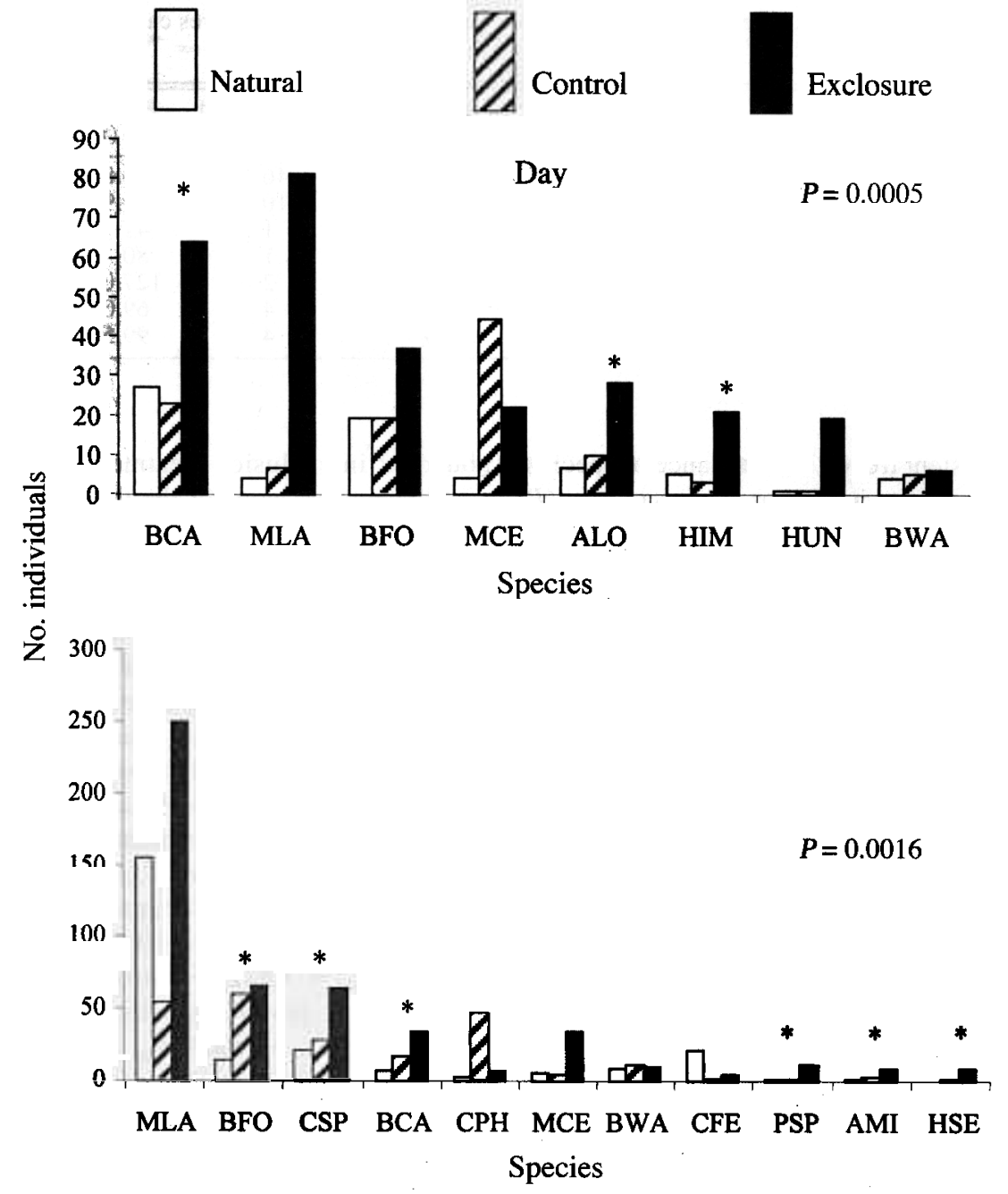

FIG. 3. Plots of abundance of individual species among treatments (summed across blocks) in day and night sampling, revealing response of multiple species to piscivore exclusion. Rare species (i.e., $<10$ individuals collected) are not depicted in the figure. $P$ values represent results of MANOVA with experimental treatment as the independent variable and species standardized abundance as the dependent variable. Significant univariate tests (i.e., one-way ANOVA, $P<0.05$ ) for individual species are indicated with an asterisk. Species codes: BCA, Bryconops caudomaculatus; MLA, Moenkhausia af. lepidura; BFO, Bivibranchia fowleri; MCE, Moenkhausia cf. ceros; ALO, Argonectes longiceps; HIM, Hemiodus immaculatus; HUN, Hemiodus unimaculatus; BWA, Biotodoma wavrini; CSP, Cyphocharax spilurus; CPH, Creagrutus phasma; CFE, Cyphocharax festivus; PSP, Pimelodella sp.; AMI, Acestrorhynchus minimus; HSE, Hemiodus semitaeniatus.

whether assemblages differed significantly according to treatment or experimental block. We used MANOVA to test for significance of these two factors, with the first four canonical axes serving as dependent variables.

\section{RESULTS}

There were no significant treatment effects on total abundance of fishes in either day $\left(F_{2,10}=0.76, P=\right.$ 0.49 ) or night $\left(F_{2,10}=2.04, P=0.18\right)$ samples (Fig. $2)$. Abundance of medium fishes for both day $\left(F_{2,10}=\right.$ 4.26, $P=0.046)$ and night $\left(F_{2,10}=12.06, P=0.002\right)$ was significantly different among treatments. In day samples, abundance of medium fishes was $383 \%$ greater in experimental than in natural plots, and $248 \%$ greater than in control treatments. For night samples, abundance of medium fishes was $148 \%$ and $91 \%$ greater in experimental treatments relative to natural plots and control treatments, respectively. Total species density was not significantly different among treatments in day samples $\left(F_{2,10}=1.14, P=0.36\right)$, but treatments were significant for night samples $\left(F_{2,10}=5.41, P=\right.$ 0.03 ). Exclosures averaged an increase of 3.7 species over natural plots and 3.0 over control treatments in night samples. This greater overall species density in enclosures is largely attributable to a response by medium fishes (increases of 4.0 and 2.2 species relative to natural and control areas, respectively). For both day $\left(F_{2,10}=14, P<0.001\right)$ and night $\left(F_{2,10}=8.05, P=\right.$ 0.008 ) samples, species density of medium fishes differed significantly among treatments. For small fishes. 
TABLE 1. Stomach contents summary of the seven most common piscivores captured on river sandbanks in the Río Cinaruco.

\begin{tabular}{|c|c|c|c|c|}
\hline Species & $\begin{array}{l}\text { Number } \\
\text { examined }\end{array}$ & $\begin{array}{c}\text { Empty } \\
\text { stomachs }(\%)\end{array}$ & $\begin{array}{l}\text { No. measured } \\
\text { prev }\end{array}$ & $\begin{array}{c}\text { Prey length } 4 \\
(\mathrm{~mm})\end{array}$ \\
\hline$\overline{\text { Boulengerella cuvieri }}$ & $\overline{203}$ & $\overline{78}$ & 46 & $68.8(21.5)$ \\
\hline Boulengerella lucius & 71 & 85 & 10 & $69.9(20.9)$ \\
\hline Cichla intermedia & 47 & 97 & 1 & $41(-)$ \\
\hline Cichla orinocensis & 41 & 95 & & $80(-)$ \\
\hline Cichla temensis & 34 & 91 . & $i$ & $127.0(82.0)$ \\
\hline Hydrolycus armatus & 48 & 83 & 4 & $69.0(41.0)$ \\
\hline Pseudoplatystoma fasciatum & 5 & 20 & 4 & $99.5(31.8)$ \\
\hline
\end{tabular}

there were no consistent trends in abundance or species density among treatments in day or night samples $(P$ $>0.16$ for each test). Abundance and species density of fishes were consistently higher in night samples, consistent with results of previous day-night faunal comparisons (Arrington and Winemiller 2003).

To test whether the overall response of medium fishes was due to multiple taxa, we performed a MANOVA on standardized species abundance ( $Z$ scores). There was a significant effect of treatment in both day (Wilks' lambda $=0.022, F_{16,16}=5.77, P=0.0005$ ) and night (Wilks' lambda $=0.0038, F_{22,10}=6.92, P=0.0016$ ) samples, with a consistent trend of highest abundance of species in exclusion treatments. Subsequent univariate analyses revealed that 5 of 8 species in day samples, and 7 of 11 species in night samples, were significantly more abundant in exclusion treatments $(P \leq$ 0.05 in all cases).

Three species were collected in sufficient numbers in night samples to evaluate potential size-dependent intraspecific responses. Medium individuals of all three species displayed highly significant differences in abundance among treatments (Moenkhausia af. lepidura, $F_{2,15}=24.21, P<0.001 ;$ Bryconops caudomaculatus, $F_{2,15}=12.00, P<0.001 ;$ Bivibranchia fowleri, $\left.F_{2,15}=17.53, P<0.001\right)$. For all three species, Tukey's post hoc test indicated medium individuals were most

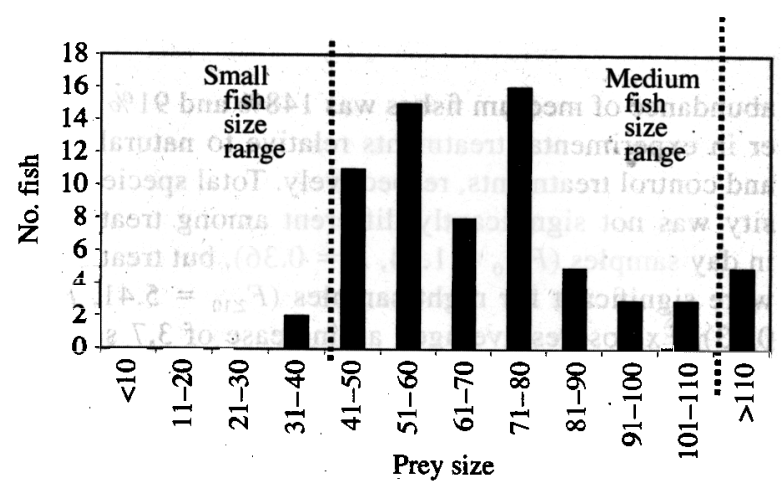

FIG 4. Frequency histogram of prey fishes as determined by stomach content analyses of the seven most common largebodied piscivores in Río Cinaruco. These data are restricted to those individuals captured on main river sandbanks, and data are pooled across piscivore taxa. abundant in exclusion treatments. In contrast, for the small size class, none of the three species showed significant differences in abundance among treatments (Moenkhausia af. lepidura, $F_{2,15}=1.75, P=0.21$; Bryconops caudomaculatus, $F_{2,15}=2.60, P=0.11$; Bivibranchia fowleri $F_{2,15}=0.01, P=0.99$ ).

Although there were significant differences in measures of abundance and species density among treatments for medium fishes, consistent assemblage-level patterns of medium fishes were not observed among treatments. Correspondence analysis revealed no significant grouping of treatments in ordination space. A MANOVA using canonical ordination scores revealed no significant effect of treatment (day, Wilks' lambda $=0.78, F_{8,14}=0.64, P=0.73$; night, Wilks' lambda $=0.37, F_{8,14}=1.1, P=0.40$ ). There was a significant experimental block (i.e., location) effect for night (Wilks' lambda $=0.005, F_{20,24.2}=4.9, P<0.001$ ) and marginally significant effect for day (Wilks' lambda = $0.21, F_{20,24.2}=1.97, P=0.057$ ) samples. Experimental block predicted assemblage composition better than treatment because species composition was more similar within a block of the experiment than across blocks for a given treatment.

We recovered 68 measurable prey fish (by volume, $>99 \%$ of identifiable stomach contents were fishes) from 449 large-bodied piscivores captured on sandbanks (Table 1). Prey sizes in stomach contents coincided with the size class that responded to predator exclusion (Fig. 4). Despite high abundance of small fishes on beaches (see Methods), 90.0\% of prey in stomachs were within $40-110 \mathrm{~mm}$. The most common identified prey were Moenkahusia af. lepidura, B. caudomaculatus, and hemiodid species. These species were also the most common medium fishes collected from experimental areas, and those that showed the strongest responses to predator exclusion. Importantly, medium prey found in piscivore stomachs was not an artifact of sampling methodology or digestive rates of different-sized prey. Extensive stomach contents analyses of the same seven piscivore species collected from lagoons in the Río Cinaruco floodplain revealed significantly smaller prey sizes compared to piscivores from sandbanks (Mann-Whitney, $T=19,654.0, P<$ 0.001 ; sandbank prey SL, $71.8 \pm 24.8$; lagoon prev 
SL, $34.0 \pm 31.2$ ). On sandbanks, $97 \%$ of piscivore prey were $>40 \mathrm{~mm}(n=68)$, compared to $24 \%$ in lagoons $(n=308)$.

\section{Discussion}

This study extends findings from temperate systems concerning size-dependent responses of fish prey to predators (Werner et al. 1983, Werner and Hall 1988, Harvey and Stewart 1991) and suggests a behavioral response that occurred in multiple species $(n>13)$ in a highly connected food web. Only by partitioning the prey fish assemblage into size categories was an effect of piscivore exclusion apparent, with medium fish (i.e., $>40 \mathrm{~mm}$ ) responding to piscivore exclusion. Predation effects in tropical fish communities has been inferred from stomach contents analysis (Goulding 1980, Winemiller 1989, 1990, Jepsen et al. 1997), comparisons of species assemblages among sites (Rodríguez and Lewis 1994, 1997), isotopic analyses (Jepsen and Winemiller 2002), and life history strategies (Reznick and Bryga 1987, Reznick et al. 2001). In the present study, the effect of predators on prey distribution was demonstrated experimentally using large field exclosures.

In "open" ecological experiments, organisms are allowed to pass in and out of experimental areas (Cooper et al. 1990). When the area over which organisms move is greater than size of experimental units, effects are primarily due to behavioral responses (Cooper et al. 1990, Englund 1997). In the present study, exclosures were large, but probably were smaller than the area covered by daily movements of most predator and prey species. In this system, some species apparently can perceive relative risk of predation and select littoral habitats accordingly. This adds to growing evidence of the importance of nonlethal responses in predator-prey interactions (Lima and Dill 1990, Abrams et al. 1996, Lima 1998, 2002, Sih et al. 1998) and highlights the need to incorporate behavioral traits into models of community dynamics (Abrams 1995, Luttbeg and Schmitz 2000, Schmitz 2000).

Adaptive behavioral responses to predation threat can have significant implications at both community and ecosystem levels. Habitat shifts induced by predators can affect feeding and/or growth rates of prey (e.g., Werner 1991, Fraser and Gilliam 1992, Turner 1997, Schmitz and Suttle 2001, Peacor 2002). Some of the medium fish that responded to predator exclusion (e.g., hemiodid species) are algivores/detritivores, and the habitat shifts displayed by these species may have important implications for the distribution of basal food resources. Behavior-mediated interactions have been found to have cascading effects on lower trophic levels in both terrestrial (Beckerman et al. 1997, Schmitz et al. 1997, Gastreich 1999) and aquatic (e.g., Power et al. 1985, Peckarsky and McIntosh 1998, Diehl et al. 2000, Turner et al. 2000, Bernot and Turner 2001) ecosystems. We are currently conducting experiments in the Río Cinaruco to examine cascading effects of algivore/detritivore species on benthic productivity.

Although aggregate measures in this study (abundance and species density) revealed significant effects to piscivore exclusion by medium fishes, multivariate analysis (the composition measure, $\mathrm{CA}$ ) revealed no differences in assemblage composition among treatments. Significant variability in species composition existed among assemblages at different sites, but the size-specific response reflected in aggregate assemblage measures occurred at all sites. Other studies have emphasized predation effects on the composition of fish assemblages (Tonn and Magnuson 1982, He and Kitchell 1990, Rodríguez and Lewis 1997, MacRae and Jackson 2001), but in the current study variability among local assemblages masked detection of consistent shifts in composition. Yet regardless of the assemblage at a given site, a general response within the local assemblage could be predicted based on body size. This demonstrates that general species characteristics can be powerful predictors of the outcome of multispecies interactions in complex food webs.

Can the results of the present study, conducted at a relatively small scale, be used to predict populationand ecosystem-level patterns (see Lima 1998)? For example, results of small-scale behavioral experiments predict watershed-level distributions of a killifish in Trinidad (Fraser et al: 1995), and $\mathrm{He}$ and Kitchell (1990) showed how laboratory and field experiments could be used to predict fish emigration following introduction of a large piscivore (northern pike, Esox lucius) in a whole-lake experiment. In the Río Cinaruco, lagoons in which piscivore populations have been greatly reduced by commercial netters are dominated numerically by the prey species that responded strongly to piscivore exclusion (e.g., Moenkahusia af. lepidura, $B$. caudomaculatus). In lagoons that still support large numbers of piscivorous fishes, assemblages are dominated numerically by species that attain lengths $<40$ $\mathrm{mm}$ (Layman and Winemiller, unpublished manuscript). Similarly, body size has been used to predict phytoplankton community shifts in response to nutrient and food web manipulations (Cottingham 1999, Klug and Cottingham 2001) and model human impacts on fishing stocks (Rice and Gislason 1996, Shin and Cury 2001).

Juanes and Conover (1994) suggested that prey selection by many piscivores is relatively passive, driven by size-related differences in prey encounter and capture probabilities. During the dry season in the Río Cinaruco, larger prey $(>110 \mathrm{~mm})$ are less abundant than earlier in the year, apparently due to intense predation during gradual recession of floodwaters (Jepsen et al. 1997). Thus, piscivores on sandbanks may select fishes in the medium size range, thereby maximizing profitability (sensu Scharf et al. 2002). In our experiment, prey within this size range responded to predation risk, suggesting a "trait-compensation" response. 
an adaptive behavioral response to compensate for vulnerability to predation (Dewitt et al. 1999, Rundle and Brönmark 2001).

In addition to large piscivores, our exclusion treatment also excluded other large fishes, including common algivore/detritivores (e.g., Semaprochilodus kneri). Algivore/detritivores have strong effects on sediments, primary production, and invertebrates in other tropical systems (Power 1984, Pringle et al. 1993, 1999, Flecker 1996, Pringle and Hamazaki 1997, Flecker et al. 2002), and increased abundance of medium fishes could have been a response to increased benthic primary production in exclusion areas. Four pieces of evidence suggest this was unlikely. First, correspondence between size of fishes that responded to experimental manipulations and those found in stomach contents of piscivores strongly suggests a response to piscivore exclusion. Second, additional experiments have demonstrated that when piscivores are enclosed within similar experimental arenas, medium fishes avoid these areas (C. A. Layman and K. O. Winemiller, unpublished manuscript). Third, the two most commonly collected medium fishes (Moenkhausia af. lepidura, Bryconops caudomaculatus) are primarily insectivores that feed at the surface or midwater. These species would not be expected to respond directly to enhanced benthic primary production. Finally, many small fishes collected in samples were algivore/detrivores, but these small species did not respond to largefish exclusion. Lack of detectable response by small fishes, however, might also be attributable to the fact that small piscivores were able to pass through the large mesh of exclosures.

Manipulation of entire "guilds" of organisms has been criticized as being "mechanism-free" (sensu Dunham and Beaupre 1998), despite notable predictive success in some instances (e.g., Marquis and Whelan 1994, Schmitz and Sokol-Hessner 2002). In speciesrich ecosystems, however, experimental manipulation of every pair of interacting species is impossible. An alternative approach is to examine multiple interacting species as a group and to rely on additional factors to infer mechanisms. Our study demonstrated how body size can be used to predict responses of multiple prey species to multiple predators. Use of size, and other traits, to predict outcomes of multiple species interactions might provide a means to aggregate food web elements and facilitate study of complex food webs.

\section{ACKNOWLEDGMENTS}

Don Taphorn of Universidad de Los Llanos Occidentales (UNELLEZ) assisted with logistics and fish identification. Fish collections were made with fishing permit No. 0439 issued by the Servicio Autonomo de los Recursos Pesqueros y Acuicolas of Venezuela. Edgar Pelaéz, Glenn Webb, Jim Marzoula, and Carol Marzoula provided invaluable logistical support through the Cinaruco River Fishing Club and Tour Apure. Albrey Arrington, Alex Flecker, David Hoeinghaus, Brian Langerhans, Brian Silliman, and two anonymous reviewers provided very helpful comments on earlier versions of the manuscript. Brain Langerhans provided significant assistance with statistical analyses. We thank the numerous people involved with field collections on the Cinaruco, and those who helped with fish identification and sorting at the Museo de Ciencias Naturales in Guanare. This work was funded by an U.S. Environmental Protection Agency Science to Achieve Results Graduate Fellowship, William "Bill" Baab Conservation Fellowship, Texas A \& M Regents and Tom Slick Fellowships, and National Science Foundation grant \# DEB0089834.

\section{Literature Cited}

Abrams, P. A. 1992. Predators that benefit prey and prey that harm predators: unusual effects of interacting foraging adaptations. American Naturalist 140:573-600.

Abrams, P. A. 1995. Implications of dynamically variable traits for identifying, classifying, and measuring direct and indirect effects in ecological communities. American Naturalist 146:112-134.

Abrams, P., B. A. Menge, G. G. Mittelbach, D. Spiller, and P. Yodzis. 1996. The role of indirect effects in food webs. Pages 371-395 in G. A. Polis and K. O. Winemiller, editors. Food webs: integration of patterns and processes. Chapman and Hall, New York, New York, USA.

Arrington, D. A., and K. O. Winemiller. 2003. Diel changeover in sandbank fish assemblages in a Neotropical floodplain river. Journal of Fish Biology 63:442-459.

Beckerman, A. P., M. Uriarte, and O. J. Schmitz. 1997. Experimental evidence for a behavior-mediated trophic cascade in a terrestrial food chain. Proceedings of the National Academy of Sciences of the USA 94:10 735-10 738 .

Bernot, R. J., and A. M. Turner. 2001. Predator identity and trait-mediated indirect effects in a littoral food web. Oecologia 129:139-146.

Cooper, S. D., S. J. Walde, and B. L. Peckarsky. 1990. Prey exchange rates and the impact of predators on prey populations in streams. Ecology 71:1503-1514.

Cottingham, K. L. 1999. Nutrients and zooplankton as multiple stressors of phytoplankton communities: evidence from size structure. Limnology and Oceanography 44:810827.

Dewitt, T. J., A. Sih, and J. A. Hucko. 1999. Trait compensation and cospecialization in a freshwater snail: size, shape and antipredator behavior. Animal Behaviour 58:397-407.

Dial, R., and J. Roughgarden. 1995. Experimental removal of insectivores from rain forest canopy: direct and indirect effects. Ecology 76:1821-1834.

Diehl, S., S. D. Cooper, K. W. Kratz, R. M. Nisbet, S. K. Roll, S. W. Wiseman, and T. M. Jenkins, Jr. 2000. Effects of multiple, predator-induced behaviors on short-term producer-grazer dynamics in open systems. American Naturalist 156:293-313.

Dunham, A. E., and S. J. Beaupre. 1998. Ecological experiments: scale, phenomenology, mechanism, and the illusion of generality. Pages 27-49 in W. J. Resetarits, Jr. and J. Bernardo, editors. Experimental ecology. Oxford University Press, New York, New York, USA.

Eklöv, P., and T. VanKooten. 2001. Facilitation among piscivorous predators: effects of prey habitat use. Ecology 82:2486-2494.

Englund, G. 1997. Importance of spatial scale and prey movements in predator caging experiments. Ecology 78:23162325.

Flecker, A. S. 1996. Ecosystem engineering by a dominant detritivore in a diverse tropical stream. Ecology 77:18451854.

Flecker, A. S., B. W. Taylor, E. S. Bernhardt, J. M. Hood, W. K. Cornwell, S. R. Cassatt, M. J. Vanni, and N. S. Altman. 2002. Interactions between herbivorous fishes and limiting nutrients in a tropical stream ecosystem. Ecology 83:18311844. 
Fox, J. W., and E. Olsen. 2000. Food web structure and the strength of transient indirect effects. Oikos 90:219-226.

Fraser, D. F., and J. F. Gilliam. 1992. Nonlethal impacts of predator invasion: facultative suppression of growth and reproduction. Ecology 73:959-970.

Fraser, D. F., J. F. Gilliam, and T. Yip-Hoi. 1995. Predation as an agent of population fragmentation in a tropical watershed. Ecology 76:1461-1472.

Gastreich, K. R. 1999. Trait-mediated indirect effects of a theridiid spider on an ant-plant mutualism. Ecology 80: 1066-1070.

Gilliam, J. F., and D. F. Fraser. 2001. Movement in corridors: enhancement by predation threat, disturbance, and habitat structure. Ecology 82:258-273.

Gotelli, N. J., and R. K. Colwell. 2001. Quantifying biodiversity: procedures and pitfalls in the measurement and comparison of species richness. Ecology Letters 4:379391.

Goulding, M. 1980. The fishes and the forest. University of California Press, Berkeley, California, USA.

Greenberg, R., P. Bichier, A. C. Angon, C. MacVean, R. Perez, and E. Cano. 2000. The impact of avian insectivory on arthropods and leaf damage in some Guatemalan coffee plantations. Ecology 81:1750-1755.

Harvey, B. C. 1991. Interactions among stream fishes: predator-induced habitat shifts and larval survival. Oecologia 87:29-36.

Harvey, B. C., and A. J. Stewart. 1991. Fish size and habitat depth relationships in headwater streams. Oecologia 87: 336-342.

He, X., and J. F. Kitchell. 1990. Direct and indirect effects of predation on a fish community: a whole-lake experiment. Transactions of the American Fisheries Society 119:825835.

Hill, M. O., and H. G. J. Gauch. 1980. Detrended correspondence analysis: an improved ordination technique. Vegetatio 42:47-58.

Jepsen, D. B., and K. O. Winemiller. 2002. Structure of tropical river food webs revealed by stable isotope ratios. Oikos 96:46-55.

Jepsen, D. B., K. O. Winemiller, and D. C. Taphorn. 1997. Temporal patterns of resource partitioning among Cichla species in a Venezuelan blackwater river. Journal of Fish Biology 51:1085-1108.

Juanes, F, and D. O. Conover. 1994. Piscivory and prey size selection in young-of-the-year bluefish: predator preference or size-dependent capture success? Marine Ecology Progress Series 114:59-69.

Klebanoff, A., and A. Hastings. 1994. Chaos in one-predator, 2-prey models-general results from bifurcation-theory. Mathematical Biosciences 122:221-233.

Klug, J. L., and K. L. Cottingham. 2001. Interactions among environmental drivers: community responses to changing nutrients and dissolved organic carbon. Ecology 82:33903403.

Lima, S. L. 1998. What are the ecological effects of antipredator decision-making. BioScience 48:25-34.

Lima, S. L. 2002. Putting predators back into behavioral predator-prey interactions. Trends in Ecology and Evolution 17:70-75.

Lima, S. L., and L. M. Dill. 1990. Behavioral decisions made under the risk of predation: a review and prospectus. Canadian Journal of Zoology 68:619-640.

Luttbeg, B., and O. J. Schmitz. 2000. Predator and prey models with flexible individual behavior and imperfect information. American Naturalist 155:669-683.

MacRae, P. S. D., and D. A. Jackson. 2001. The influence of smallmouth bass (Micropterus dolomieu) predation and habitat complexity on the structure of littoral zone fish assemblages. Canadian Journal of Fisheries and Aquatic Sciences 58:342-351.

Marquis, R. J., and C. J. Whelan. 1994. Insectivorous birds increase growth of white oak through consumption of leafchewing insects. Ecology 75:2007-2014.

McGuire, T. L., and K. O. Winemiller. 1998. Occurrence patterns, habitat associations, and potential prey of the river dolphin, Inia geoffrensis, in the Cinaruco River, Venezuela. Biotropica 30:625-638.

Micheli, F, K. L. Cottingham, J. Bascompte, O. N. Bjørnstad, G. L. Eckert, J. M. Fischer, T. H. Keitt, B. E. Kendall, J. L. Klug, and J. A. Rusak. 1999. The dual nature of community variability. Oikos 85:161-169.

Nyström, P., O. Svensson, B. Lardner, C. Brönmark, and W. Granéli. 2001. The influence of multiple introduced predators on a littoral pond community. Ecology 82:1023-1039.

Peacor, S. D. 2002. Positive effects of predators on prey growth rate through induced modifications of prey behaviour. Ecology Letters 5:77-85.

Peckarsky, B. L., and A. R. McIntosh. 1998. Fitness and community consequences of avoiding multiple predators. Oecologia 113:565-576.

Peet, R. K., R. G. Knox, J. S. Case, and R. B. Allen. 1988. Putting things in order: the advantages of detrended correspondence analysis. American Naturalist 131:924-934.

Peterson, C. H., and S. V. Andre. 1980. An experimental analysis of interspecific competition among marine filter feeders in a soft-sediment environment. Ecology 61:129139.

Polis, G. A., and D. R. Strong. 1996. Food web complexity and community dynamics. American Naturalist 147:813846.

Power, M. E. 1984. Habitat quality and the distribution of algae-grazing catfish in a Panamanian stream. Journal of Animal Ecology 53:357-374.

Power, M. E., W. J. Matthews, and A. J. Stewart. 1985. Grazing minnows, piscivorous bass, and stream algae: dynamics of a strong interaction. Ecology 66:1448-1456.

Pringle, C. M., G. A. Blake, A. P. Covich, K. M. Buzby, and A. Finley. 1993. Effects of omnivorous shrimp in a montane tropical stream: sediment removal, disturbance of sessile invertebrates and enhancement of understory algal biomass. Oecologia 93:1-11.

Pringle, C. M., and T. Hamazaki. 1997. Effects of fishes on algal response to storms in a tropical stream. Ecology 78: 2432-2442.

Pringle, C. M., N. Hemphill, W. H. McDowell, A. Bednarek, and J. G. March. 1999. Linking species and ecosystems: different biotic assemblages cause interstream differences in organic matter. Ecology 80:1860-1872.

Relyea, R. A., and K. L. Yurewicz. 2002. Predicting community outcomes from pairwise interactions: integrating density- and trait-mediated effects. Oecologia 131:569579.

Reznick, D. N., and H. Bryga. 1987. Life history evolution in guppies (Poecilia reticulata): 1. Phenotypic and genetic changes in an introduction experiment. Evolution 41:13701385.

Reznick, D., M. J. Butler, and H. Rodd. 2001. Life-history evolution in guppies. VII. The comparative ecology of high- and low-predation environments. American Naturalist 157:126-140.

Rice, J., and H. Gislason. 1996. Patterns of change in the size spectra of numbers and diversity of the North Sea fish assemblage, as reflected in surveys and models. ICES Journal of Marine Science 53:1214-1225.

Rodríguez, M. A., and W. M. Lewis, Jr. 1994. Regulation and stability in fish assemblages of neotropical floodplain lakes. Oecologia 99:166-180. 
Rodríguez, M. A., and W. M. Lewis, Jr. 1997. Structure of fish assemblages along environmental gradients in floodplain lakes of the Orinoco River. Ecological Monographs 67:109-128.

Rundle, S. D., and C. Brönmark. 2001. Inter- and intraspecific trait compensation of defence mechanisms in freshwater snails. Proceedings of the Royal Society of London B, Biological Sciences 268:1463-1468.

Scharf, F. S., J. A. Buckel, and F. Juanes. 2002. Size-dependent vulnerability of juvenile bay anchovy Anchoa mitchilli to bluefish predation: does large body size always provide a refuge? Marine Ecology Progress Series 233:241-252.

Scheiner, S. M., and J. Gurevitch. 2001. Design and analysis of ecological experiments. Oxford University Press, New York, New York, USA.

Schmitz, O. J. 1998. Direct and indirect effects of predation and predation risk in old-field interaction webs. American Naturalist 151:327-342.

Schmitz, O. J. 2000. Combining field experiments and individual-based modeling to identify the dynamically relevant organizational scale in a field system. Oikos 89:471484.

Schmitz, O. J., A. P. Beckerman, and K. M. O'Brien. 1997. Behaviorally mediated trophic cascades: effects of predation risk on food web interactions. Ecology 78:1388-1399.

Schmitz, O., and L. Sokol-Hessner. 2002. Linearity in the aggregate effects of multiple predators in a food web. Ecology Letters 5:168-172.

Schmitz, O. J., and K. B. Suttle. 2001. Effects of top predator species on direct and indirect interactions in a food web. Ecology 82:2072-2081.

Schoener, T. W., and D. A. Spiller. 1999. Indirect effects in an experimentally staged invasion by a major predator. American Naturalist 153:347-358.

Schoener, T. W., D. A. Spiller, and J. B. Losos. 2002. Predation on a common Anolis lizard: can the food-web effects of a devastating predator be reversed? Ecological Monographs 72:383-407.

Shin, Y., and P. Cury. 2001. Exploring fish community dynamics through size-dependent trophic interactions using a spatialized individual-based model. Aquatic Living Resources 14:65-80.

Sih, A., G. Englund, and D. Wooster. 1998. Emergent impacts of multiple predators on prey. Trends in Ecology and Evolution 13:350-355.

Spiller, D. A., and T. W. Schoener. 2001. An experimental test for predator-mediated interactions among spider species. Ecology 82:1560-1570.

Steinmetz, J., S. L. Kohler, and D. A. Soluk. 2003. Birds are overlooked top predators in aquatic food webs. Ecology 84:1324-1328. ter Braak, C. J. F., and P. Šmilauer. 1998. Reference manual and user's guide to CANOCO for Windows: software for canonical community ordination. Version 4. Microcomputer Power, New York, New York, USA.

Tonn, W. M., and J. J. Magnuson: 1982. Patterns in the species composition and richness of fish assemblages in northern Wisconsin lakes. Ecology 63:1149-1166.

Turner, A. M. 1997. Contrasting short-term and long-term effects of predation risk on consumer habitat use and resources. Behavioral Ecology 8:120-125.

Turner, A. M., R. J. Bernot, and C. M. Boes. 2000. Chemical cues modify species interactions: the ecological consequences of predator avoidance by freshwater snails. Oikos 88: $148-158$.

Turner, A. M., and G. C. Mittelbach. 1990. Predator avoidance and community structure: interactions among piscivores, planktivores, and plankton. Ecology 71:2241-2254.

Werner, E. E. 1991. Nonlethal effects of a predator on competitive interactions between two anuran larvae. Ecology 72:1709-1720.

Werner, E. E., J. F. Gilliam, D. J. Hall, and G. G. Mittelbach. 1983. An experimental test of the effects of predation risk on habitat use in fish. Ecology 64:1540-1548.

Werner, E. E., and D. J. Hall. 1988. Ontogenic habitat shifts in bluegill: the foraging rate-predation risk tradeoff. Ecology 69:1352-1366.

Wilbur, H. M., and J. E. Fauth. 1990. Experimental aquatic food webs: interactions between two predators and two prey. American Naturalist 135:176-204

Winemiller, K. O. 1989. Ontogenetic diet shifts and resource partitioning among piscivorous fishes in the Venezuelan llanos. Environmental Biology of Fishes 26:177-199.

Winemiller, K. O. 1990. Spatial and temporal variation in tropical fish trophic networks. Ecological Monographs 60: 331-367.

Winemiller, K. O., and D. B. Jepsen. 1998. Effects of seasonality and fish movement on tropical river food webs. Journal of Fish Biology 53:267-296.

Wootton, J. T. 1993. Indirect effects and habitat use in an intertidal community: interaction - chains and interaction modifications. American Naturalist 141:71-89.

Wootton, J. T. 1994. Putting the pieces together: testing the independence of interactions among organisms. Ecology 75:1544-1551.

Wootton, J. T. 2001. Prediction in complex communities: analysis of empirically derived Markov models. Ecology 82:580-598.

Yodzis, P. 2000. Diffuse effects in food webs. Ecology 81: 261-266.

Zar, J. H. 1996. Biostatistical analysis. Prentice Hall, Upper Saddle River, New Jersey, USA. 